\title{
Methods of Extending the Strawberry Season in Europe
}

Jim Hancock ${ }^{1}$ and David Simpson ${ }^{2}$

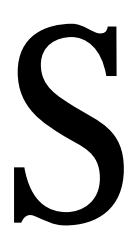

trawberries are no longer a seasonal fruit. It is now common to find fresh strawberries throughout the year in almost all markets of the world. This market expansion began in North America with improvements in the shipability of fruit and the development of annual, late fall, and winter planting systems for warm climates. As a result, most strawberry production in North America has shifted to California and Florida, where collectively fruit can be produced throughout the year. From 1950 to 1990, California's share of the United States market grew from $27 \%$ to $74 \%$, while Florida increased from $3 \%$ to $10 \%$ (Bringhurst et al., 1990).

The emergence of commercially acceptable day-neutral cultivars played a major role in expanding the strawberry season in North America. Day-neutrals produce fruit within 90 days of planting if temperatures are 10 to $30 \mathrm{C}$ and, as a result, can be harvested in virtually any season in warm climates depending on planting date (Bringhurst and Voth, 1984). The University of California-Davis dayneutrals 'Selva' and 'Seascape' now constitute up to $60 \%$ of the acreage in California (Sjulin, personal communication). Even in areas with cold temperatures that prevent winter growth, USDA day-neutrals such as 'Tristar' and 'Tribute' have been used to provide multiple summer crops (Chandler, 199 1; Galletta and Bringhurst, 1990).

\footnotetext{
${ }^{1}$ Professor, Department of Horticulture, Michigan State University, East Lansing, MI 48823.

'Principal research scientist, Horticultural Research International, East Malling, U.K. ME19 6BJ.

This article was stimulated by a visit to Tim and Fizzy Morton's Manor House Farm, Geldeston, Suffolk, Engand, where one of us (J.F.H.) was first exposed to the various protected strawberry systems of Europe. The manuscript was greatly improved by suggestions from Barbara L. Goulart, Dept. of Horticulture, Pennsylvania State Univ., and Marvin P. Pritts, Dept. of Fruit and Vegetable Science, Cornell Univ. The cost of publisbing this paper was defrayed in part by the payment of page charges. Under postal regulations, this paper therefore must be hereby marked advertisement solely to indicate this fact.
} 
Table 1. Characteristics of the major Strawberry production regions in Europe.

\begin{tabular}{lll}
\hline Region & Climate & Production systems \\
\hline Spain and Southern Italy & Mild Mediterranean & Open and tunnels \\
N. Italy and S.E. France & Mild, occasional cold winters & Tunnels and open \\
Germany & Continental, cold winters & Open and tunnels \\
Holland and Belgium & Continental, cold winters & Open, greenhouse, tunnels \\
U.K. and Republic of Ireland & Mild maritime & Open and tunnels \\
$\begin{array}{l}\text { Poland } \\
\text { Scandinavia }\end{array}$ & Continental, severe winters & Open Elsanta \\
& Short growing season, severe winters & Open \\
\hline
\end{tabular}

While day-neutral cultivars have begun to appear in Europe, protected systems have played a much more important role in harvest extension. In fact, tunnels and greenhouses have been used in Europe for more than 150 years (Baganel, 1939; Knight, 1833; Oldman, 1945). Protection in the form of tunnels is commonly used in Spain, Italy, France, and, to a limited extent, England and Germany. Both greenhouses and tunnels are heavily used in the Netherlands and Belgium, and floating mulches are frequently used in England. In North America, greenhouse and tunnel production is very rare, although the use of floating mulches is more common (Gast and Pollard, 1991; Pritts et al., 1989). In this article, we review strawberry production patterns in Europe and describe the types of protected systems used.

\section{Production patterns in E urope}

Seven primary production regions can be identified in Europe based on climatic conditions, cultivars, and cultural techniques (Table 1): 1) Spain, southern France, and southern Italy with continental climates and mild Mediterranean winters, 2) northern Italy and southeastern France with relatively mild temperatures, but occasional cold winters, 3) Belgium and the Netherlands wih cold continental climates that are modulated by the ocean, 4) Germany with cold continental climates, 5) United Kingdom and Ireland with mild, maritime climates, 6) Poland and central Europe with continental climates and severe winters, and 7) the Scandinavian counties with very short growing seasons and severe winters.

Total European production is about twice that of the United States (Rosati, 1993). Poland was the leading producer in 1992 with 204,519 metric tons, followed by Spain $(188,000)$, Italy $(183,641)$, France $(80,000)$, Germany $(53,172)$, and United Kingdom $(47,975)$ (FAO Production Statistics, 1992).
More than $60 \%$ of the hectarage in Spain and southern Italy is under high tunnels for early production of fresh-market fruit (Figs. 1 and 2; Rosati, 1990). Mostly frigo plants are grown in intense annual systems similar to those used in the open in California and Florida, except they are covered during the production season. Bumble bees and honey bees are often introduced to enhance pollination. Ripening begins in mid-February in Sicily and favorable Spanish locations and ends in late April to early May on later sites, when the fruit quality deteriorates due to high temperatures. The length of harvesting season varies from 2 to 4 months, depending on variety and location, and is virtually continuous but with pronounced peaks and troughs. The University of California-Davis cultivars Oso Grande, Chandler, and Pajaro are predominant, although new locally developed types are gaining in importance. 'Tudla', developed by the Spanish company Planasa, has $10 \%$ of the hectarage in the primary production region in Spain around Huelva.

About $70 \%$ of the production in France is in the south, and most is produced under low tunnels that are often opened during warm days to enhance pollination (Rosati, 1990). Walk-in tunnels and open cultural
Fig. 1. Multispan tunnels in southern Italy.

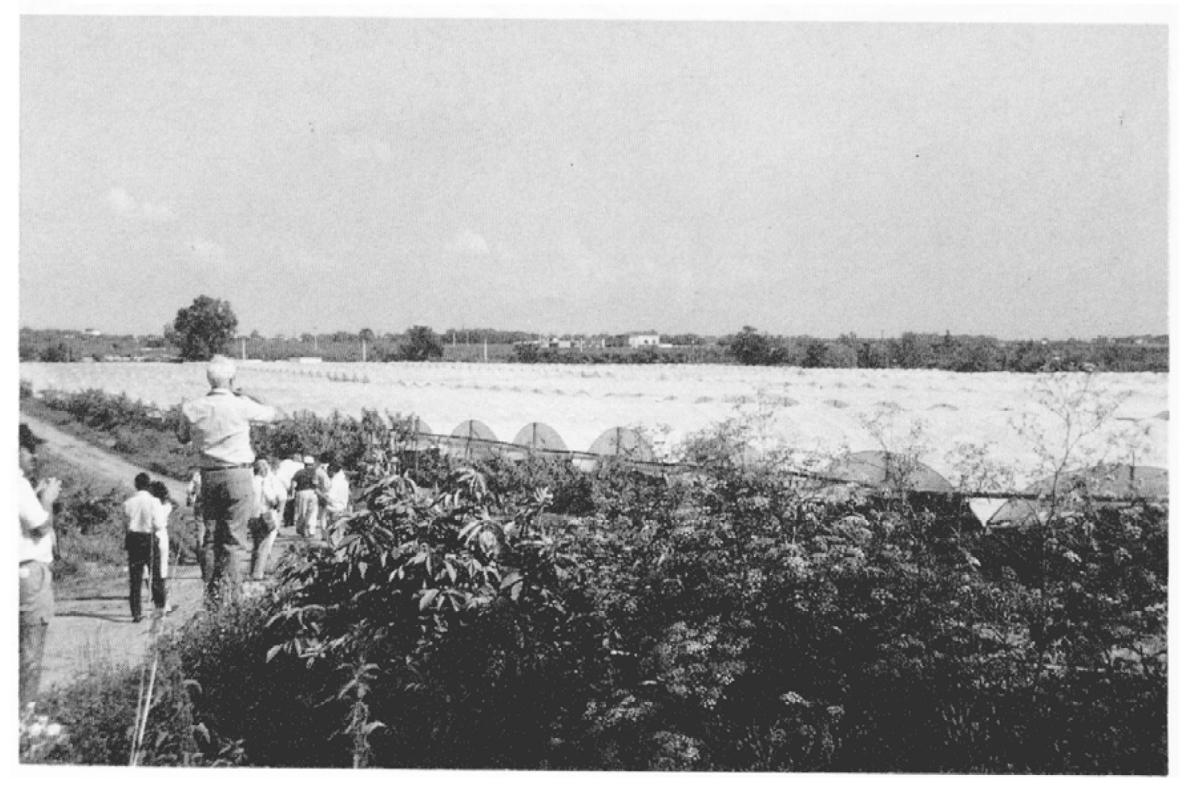




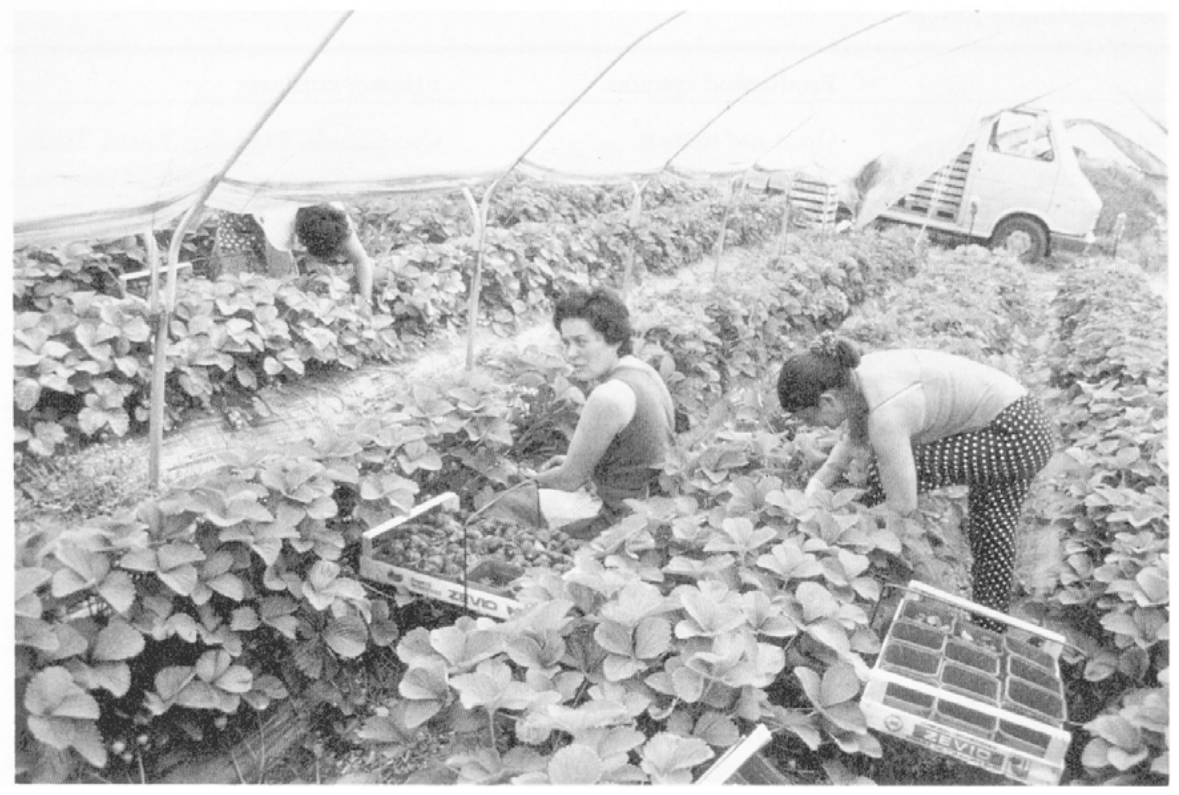

and 4) and trickle-irrigated. Harvest dates are made almost continuous by staggering planting dates of shortday cultivars outside and under protection and. by altering temperature in tunnels and greenhouses. This programmed cropping was developed using waiting-bed plants and is often referred to as the waiting-bed system. However, since other types of plants are also used, a more accurate term is the 60-day crop, referring to the length of time from planting to harvest. Yields are as high as 4.5 to 5.5 $\mathrm{kg} \cdot \mathrm{m}^{-2}$ in the greenhouse, with two or three crops per year (Lieten, 1993).

Three types of plants are used in this system: 1) graded, cold-stored runner plants from normal field propagation, 2) plants held in waiting beds outdoors at densities of $25 \times 25 \mathrm{~cm}$ before planting, or 3) plants rooted

Fig. 2. Harvesting 'Addie' near Verona in a walk-in or high tunnel.

Fig. 3. 'Elsanta' in buckets in Holland. Fram of Hein van Hemert, Ametzoden. systems are used in northern Italy. Low tunnels are cheaper to use than the high ones, but they are more poorly ventilated and cool down much more. quickly at night and consequently do not advance the season as much. Annual hill systems predominate in both of these areas. Harvests begin in April under tunnels and end in the open about June. The Dutch 'Elsanta' and French 'Gariguette' are popular in France, while Italian-bred 'Addie' and 'Marmolada' predominate in Italy.

Holland and Belgium produce fruit virtually year-round. We estimate that about $10 \%$ of the Dutch strawberries and $15 \%$ to 20 $\%$ of the Belgium strawberries are produced in greenhouses. High and low tunnels are also used to extend the outdoor season. Plants in greenhouses are maintained at moderately high densities, grown in containers (Figs. 3 and held in trays before chilling. Waiting beds are used to increase the number and size of crowns and, hence, the yield potential of plants before cold storage, but this type of plant is the most expensive to produce.

Great care is taken to maintain sterile conditions in the greenhouse, as the primary cultivar grown, 'Elsanta', is highly susceptible to root diseases (Phytophthorafia ariae), crown rot (Phytophthora cactorum), and powdery mildew (Sphaerotheca macularis F. sp. fragariae). To minimize disease spread through water, plants are commonly set in buckets suspended above the soil (Fig. 3) or bags filled with a combination of mostly peatmoss and styromull or perlite (Fig. 4). Year-round production is possible by holding dormant plants in cold storage and planting them every 6 to 8 weeks in heated greenhouses or tunnels. However, coldstored crowns are generally not planted in the late summer and early winter, as the vigor of cold stored plants deteriorates over time.

Producers in the United Kingdom and Ireland use a wide array of protected systems. Floating mulches (Fig. 5) are commonly placed over fields in the late fall to hasten the fruiting season of short-day cultivars. Likewise, low tunnels (polyethylene cloches, Fig. 6) and, more often, portable high tunnels (called French tunnels in the UK) are put over shortday plants in February to advance their crops, or they are placed over day-neutrals in August to extend the season into November. Many growers plant friigo plants in May or June, take a 60-day crop the same year, and then harvest the plants for one or two 
additional seasons. Matted rows in the open are still popular on pickyour-own farms, but runnerless culture (often with some form of protection) now dominates commercial production. The most important cultivar for the flesh market is 'Elsanta' followed by 'Pegasus' and 'Honeoye'.

Most of the German production is in open fields, but tunnels are sometimes used to advance the harvest season. Open-grown, annual hill systems predominate in the milder, southern regions, and matted rows predominate in the cooler, northern areas. 'Elsanta' is most important in Germany, with some Dutch-developed 'Korona' and 'Elvira', and German-bred 'Senga Sengana' being grown.

Poland and Scandinavia are the

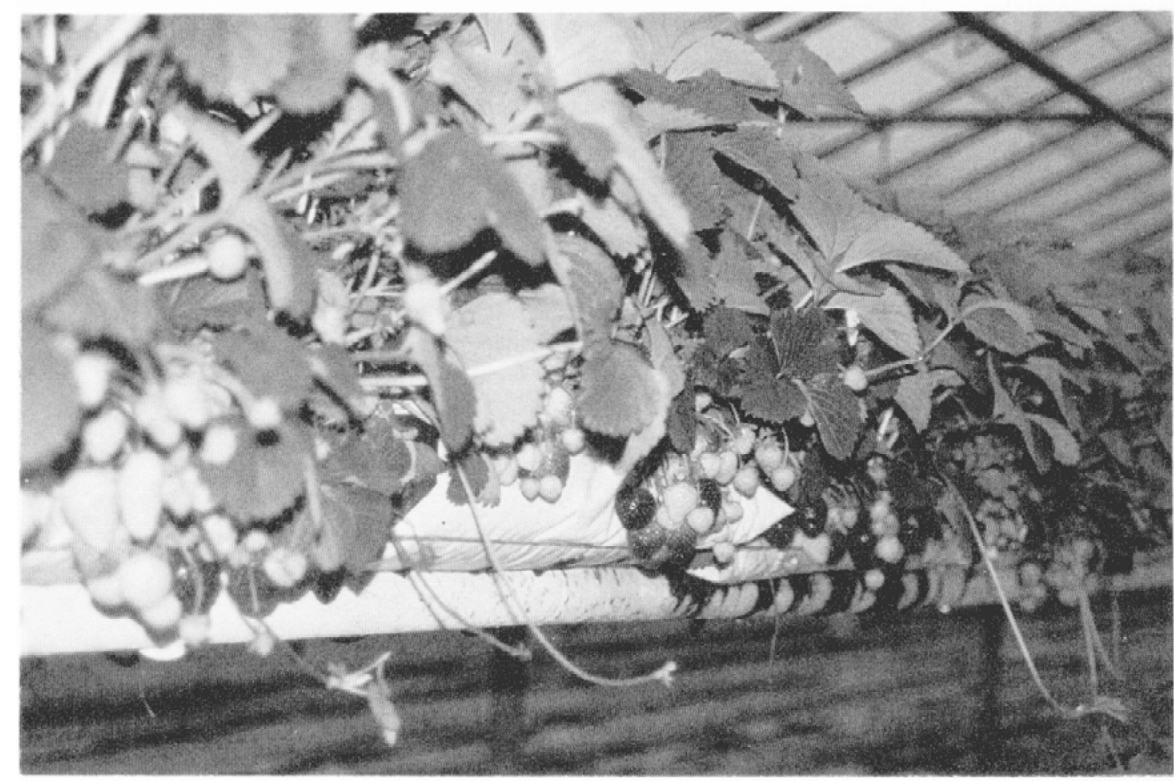
only areas in Europe where protected systems have not been used to any extent. Almost all strawberries are grown in matted rows in the open in these countries. Fruit are harvested in June in Poland and exported primarily for processing. 'Senga Sengana' is the predominant cultivar, with a limited amount of 'Elsanta' being grown for the domestic fresh market. In Scandinavia, 'Senga Sengana' also dominates, but fruit are produced primarily for the fresh market in late June to early July. Profit margins on processed fruit are too low to support protected systems in Poland because they yield fruit in the center of the European season, while the import of less-expensive, early season fruit of similar varieties reduces the profitability of tunnels in Scandinavia.

\section{Future of protected culture in Europe}

The availability of commercially acceptable day-neutrals may ultimately play an important role in determining the extent of protected culture in Europe. Improved dayneutrals would greatly broaden the harvest season in the warmer regions of Europe and might effectively compete with a portion of the protected acreage. Several European day-neutrals have been released, including 'Calypso', 'Tango', 'Evita' (United Kingdom), 'Cartcua' (Spain), 'Don' (Italy), 'Ostara', and 'Rapella' (Holland), although California's 'Selva' still dominates the limited day-neutral hectarage. It is likely that European day-neutrals will eventually become more popular than the North

American types due to better regional adaptation.

Regardless of the appearance of dayneutrals, tunnel systems will probably remain important in Europe for a long time. In the milder regions, protected systems have allowed growers to produce fruit much earlier than open systems allow, and, as a result, they have obtained the high prices associated with shipping very early fruit. Wholesale prices in the United Kingdom have averaged about $3.00 £ / \mathrm{kg}$ (about $\$ 2.40 / \mathrm{lb}$ ) in May over the last 3 years before falling to about $1.80 £ / \mathrm{kg}$ (about $\$ 1.44 / \mathrm{lb}$ ) in July (Business Consulting Development Center, ADAS, Cambridge). Spanish fruit often received in excess of $400 £ / \mathrm{kg}$ (about $3.20 \mathrm{lb}$ ) in the early winter months. In the colder, northern regions, protected systems have been profitable
Fig. 4. 'Marmolada' in bags in Belgium. Farm of Jan Royakkers, near Tongeren.

Fig. 5. Floating rowcovers in the United Kingdom. 


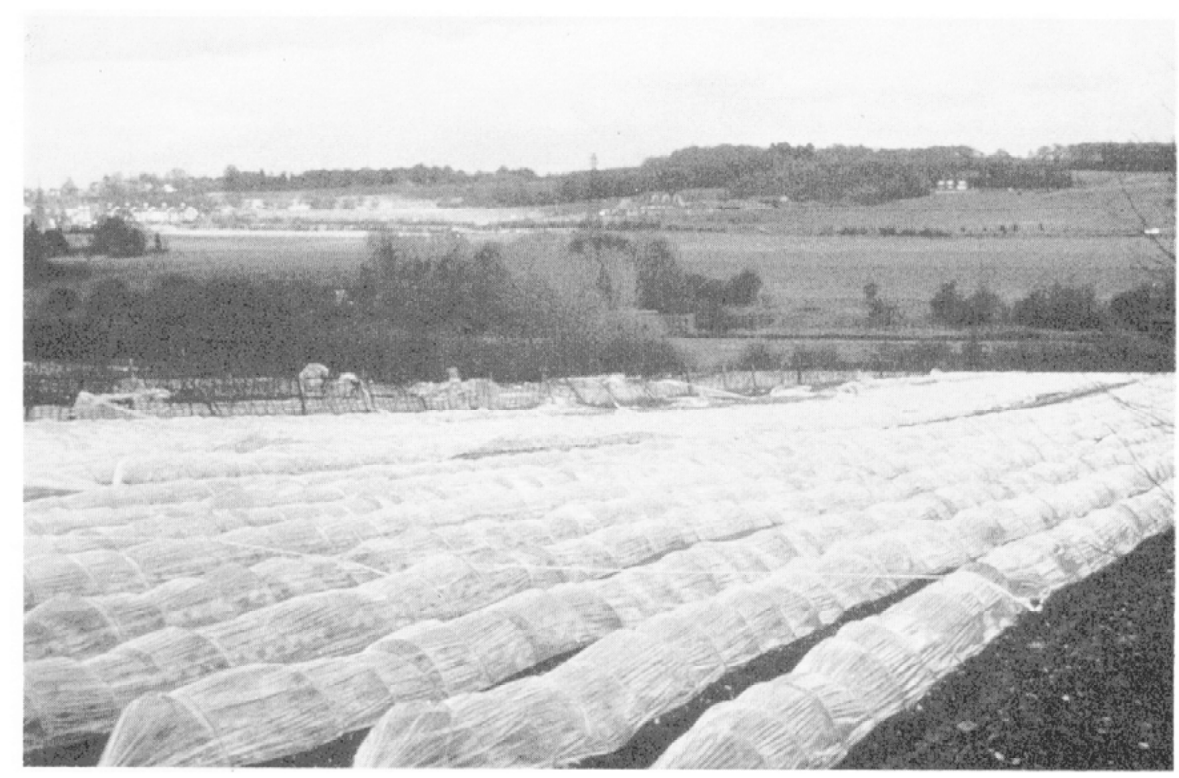

Fig. 6. Law tunnels or polyethylene cloches in the United Kingdom. where consumers are willing to pay a premium price for locally grown, off-season fruit that are perceived to be of higher quality. In fact, day-neutrals may even find an important role in tunnel culture in these regions as a means of further extending the harvest season. This is already being done on a limited scale in the Netherlands, Belgium, and the United Kingdom.

The future of greenhouse strawberries will depend to a large extent on the price of off-season fruit and whether new diseaseresistant cultivars are developed. Currently, the expensive cost of greenhouse production is offset by the high price that can be received for the fruit and the higher vigor associated with the more sterile bag-and-bucket systems. In October and November, prices have risen back to about $2.50 £ / \mathrm{kg}$ (about $\$ 2.00 /$ $\mathrm{lb})$ in the United Kingdom over the last 3 years (Business Consulting Development Center). Fruit in December can command wholesale prices as high as $500 £ / \mathrm{kg}$ (about $\$ 4.00 / \mathrm{lb})$. The susceptibility of 'Elsanta' to soilborne diseases makes it difficult to grow in the field, but its fruit are in high demand in Europe. As new cultivars appear with the quality of 'Elsanta' but improved disease resistance, it is possible that the industry will partially shift back to the more cheaply produced, field-grown fruit.

It is unclear as to why protected culture has not played a more important role in North America, since covered systems are not a new development. Climate barriers were probably not the cause, as several North American production areas have climates simil- ar to areas where tunnels and greenhouses are used in Europe. Protected culture is used in European hardiness zones 10 (Southern Italy and Spain), 8 and 9 (Northern Italy, France, Belgium, and The Netherlands), and 6 and 7 (Germany and United Kingdom), which are equivalent to coastal California (zone 10), Florida (zone 9 and 10), the Pacific Northwest (zones 8 and 9), the southern United States (zones 7 and 8), and parts of the lower midwestern and eastern United States (zones 5 and 6) (Hancock and Luby, 1995). The virtual absence of protected strawberry culture in North America is probably due to a complex array of factors, including low transportation costs, generally low food costs, a consumer reluctance to pay high prices for fresh fruit, and highly centralized marketing structures.

\section{Literature Cited}

Baganel, N.B. 1939. Fruit growing. Modem cultural methods. Ward Lock \& Co. Ltd, London.

Bringhurst, R.S. and V. Voth. 1984. Breeding octoploid strawberries. Iowa State J. Res. 58 :369-371.

Bringhurst, R.S., V. Voth and D. Shaw. 1990. University of California strawberry breeding. HortScience 25:834-835.

Chandler, C.K. 1991. North American strawberry cultivars. In: A. Dale and J.J. Luby (eds.). The strawberry into the 21st century. Timber Press, Portland, Ore.

Galletta, G.J. and R.S. Bringhurst. 1990. Strawberry management. In: G.J. Galletta and D.G. Himekick (eds.). Small fruit crop management. Prentice Hall, Englewood Cliffs, N.J.

Gast, K.L.B. and J.E. Pollard. 1991. Rowcovers enhance reproductive and vegetative yield components in strawberries. HortScience 26:1467-1469.

Hancock, J.F. And J.J. Luby. 1995. Adaptive zones and ancestry of the most important North American strawberry cultivars. Fruit Var. J. 49:85-90.

Knight, T.A. 1833. On the means of obtaining abundant autumal crops of the double-bearing Hautbois strawberry. Trans. Royal Sot. London. 1:399-400.

Leiten, F. 1993. Methods and strategies of strawberry forcing in Europe: Historical perspectives and recent developments. Acta. Hort. 348:158-170.

Oldbam, C.H. 1946. The cultivation of berried fruits in Great Britain. Crosby, Lockwood \& Son Ltd., London.

Pritts, M.P., K.A. Worden, and M.E. Sheavly. 1989. Rowcover material and time of application and removal affect ripening and yield of strawberries. J. Amer. Soc. Hort. Sci. 114:531-536.

Rosati, P. 1990. The strawberry in Europe. In: A. Dale and J. Luby (eds.). The strawberry into the 21st century. Timber Press, Portland, Ore.

Rosati, P. 1993. Recent trends in strawberry production and research: An overview. Acta Hort. 348: 23-44. 